\title{
KSIĘGA JUBILEUSZOWA DEDYKOWANA PROFESOROWI BOGDANOWI WALCZAKOWI
}

W 2013 roku w Poznaniu w Wydawnictwie Rys ukazała się trzytomowa publikacja pod redakcją Jolanty Migdał i Agnieszki Piotrowskiej-Wojaczyk: Cum reverentia, gratia, amicitia... Księga jubileuszowa dedykowana Profesorowi Bogdanowi Walczakowi, t. I ss. 628, t. II - ss. 622, t. III - ss. 628. Publikacja ta dostępna jest w bibliotekach uniwersyteckich i w Bibliotece Narodowej, nie była natomiast skierowana do sprzedaży. Aby poinformować o tej pozycji wszystkich językoznawców i zainteresować jej zawartością, zamieszczamy wykaz opublikowanych w niej artykułów.

Cum reverentia, gratia, amicitia...

Ksiega jubileuszowa dedykowana Profesorowi Bogdanowi Walczakowi pod redakcją Jolanty Migdał i Agnieszki Piotrowskiej-Wojaczyk, Poznań 2013

\section{Tom 1}

List Jego Magnificencji Rektora UAM prof. dra hab. Bronisława Marciniaka Józef Tomasz Pokrzywniak, O Jubilacie

Tabula gratulatoria

Jolanta Migdał, Agnieszka Piotrowska-Wojaczyk, Bogdan Walczak-uczony, nauczyciel, przyjaciel, po prostu OSOBOWOŚĆ

Wykaz prac Profesora Bogdana Walczaka (zestawiły: Jolanta Migdał, Agnieszka Piotrowska-Wojaczyk)

Zofia Abramowicz, Slawizacja systemu antroponimicznego Żydów podlaskich

Janina Abramowska, O poezji okolicznościowej - dawnej i nie tylko 
Mieczysław Balowski, Czeska relacja wojny Rzeczypospolitej Obojga Narodów z Gdańskiem w 1577 roku

Kinga Banderowicz, „(...) Ad ius civile suscepti.” Antroponimy Poznaniaków w rejestrach przyjęć do prawa miejskiego we Lwowie

Jerzy Bańczerowski, Izofoniczny aspekt fonotaktyki

Mirosław Bańko, Normatywista na rozdrożu. Dwugłos w sprawie tzw. kryterium narodowego

Stanisław Bąba, Jarosław Liberek, Dwa ujęcia etymologii porównania jak w dym

Leszek Bednarczuk, Les contacts linguistiques sur le territoire du Grand Duche de Lituanie (GDL)

Jerzy Biniewicz, O mierzeniu obiektów w traktacie Stanisława Grzepskiego słów kilka

Ireneusz Bobrowski, Stereotyp stereotypu językowego

Stanisław Borawski, Rękopiśmienna pamiątka ku uciesze lub do ćwiczenia w edytorstwie

filologicznym

Maria Borejszo, Sposoby identyfikacji tekstów kolędowych $w$ tzw. Kantyczkach karmelitańskich z XVII i XVIII wieku

Edward Breza, Imiona złożone typu Anna Maria

Władysława Bryła, „Homo moralis” w Moraliach Wacława Potockiego

Jerzy Brzeziński, Wkład profesora Bogdana Walczaka w kształtowanie zielonogórskiego

środowiska językoznawczego

Marian Bugajski, Kilka uwag o kulturze języka w Polsce

Andrzej Charciarek, Metatekst fatyczny w stowniku przekładowym polsko-rosyjskim

Bożena Chrząstowska, Czytanie Miłosza - w XX i XXI wieku

Aleksandra Cieślikowa, Czy możemy mówić o antonimach, synonimach w nazwach własnych?

Lilia Citko, O Leksykonie supraskim (1722) w kontekście zachodnioruskich opracowań normatywno-leksykograficznych

Marek Cybulski, O problemach z normalizacja morfonologiczna kaszubszczyzny literackiej (na przykładzie Liskawicë Stanisława Jankego)

Marek Cybulski, Diabet jako przedmiot tabuizacji językowej i eufemizacji w dawnej Polsce

Zofia Cygal-Krupa, Świat roślin w poezji Jana Twardowskiego

Stanisław Cygan, Przejawy świadomości językowej mieszkańców wsi zawarte w tekstach gwarowych $z$ potudniowego Podlasia

Grzegorz Cyran, Pedagogiczne itinerarium religijnej inwokacji wedtug Zelindo Trentiego

Magdalena Czachorowska, Kwiaty w twórczości Bolesława Prusa

Katarzyna Czarnecka, Ortograf na ortografie, czyli o tym, jak użytkownicy pewnego forum internetowego rozmawiaja o pisowni

Dorota Czyż, Nazwy ulic Kadzidła

Leonarda Dacewicz, Księgi metrykalne dawnych parafii mahometańskich w Polsce jako źródło do badania antroponimii Tatarów litewsko-polskich

Józef Paweł Darski, Granice słowoform

Krystyna Data, Najdawniejsze zapożyczenia niemieckie we współczesnej polszczyźnie

Wanda Decyk-Zięba, Wyrazy rosyjskie znane Polakom w XVI wieku

Ewa Deptuchowa, O suplemencie do Słownika staropolskiego 
Stanisław Dubisz, Język/słowo w koncepcji poezji Juliusza Słowackiego i Cypriana Norwida

Henryk Duda, Faramuszka $i$ niezapominajka (niezabudka) Dwie hipotezy etymologiczne

Bogusław Dunaj, Mirosława Mycawka, Zmienność normy w polszczyźnie literackiej (na przykładzie realizacji grupy $\mathrm{xv}$ )

Andrzej S. Dyszak, Z poszukiwań zapisów gwary bydgoskiej

Gabriela Dziamska-Lenart, O zmienności znaczeń związów frazeologicznych (na materiale Słowniczka frazeologicznego Antoniego Krasnowolskiego z końca XIX wieku)

Katarzyna Dziubalska-Kołaczyk, English or ELFish? A teaching dilemma of the 21st century

Piotr Fliciński, Frazeologia w tekstach reklamowych (część 1. - idiomy w sloganach)

Teresa Friedelówna, Językowy obraz zwierząt w Godach życia Adolfa Dygasińskiego

Sławomir Gala, Nazwiska polskie na -ak

Zygmunt Gałecki, Trzepizur. Rozprawka metodyczna

Magdalena Gawrońska-Garstka, Rola i znaczenie Uniwersytetu Stefana Batorego w wileńskim życiu kulturalnym

Magdalena Graf, Święte grzeszniczki, grzeszne świętoszki. Żywoty świętych osiedlowych Lidii Amejko pod onomastyczna lupa

Maciej Grochowski, O partykule ostatecznie. Wprowadzenie do analizy semantycznej

Aneta Grodecka, Lis czy lisica? Oto jest pytanie! Przyczynek do badań nad rodzajem gramatycznym lisiej alegorii

Eliza Grzelak, Kreacja prawdy w reklamie

Szymon Grzelak, Japońskie partykuly finalne w perspektywie kontrastywnej

Monika Grzelka, Agnieszka Kula, O stowie cudzym (i własnym jako cudzym) w tekstach naukowych. Teksty Bogdana Walczaka jako źródto cytowania

Kwiryna Handke, Znaki czasu i stereotypy - o repartycji ogólnych nazw człowieka

Magdalena Hawrysz, Walka na stowa z perspektywy genologicznej

Jolanta Ignatowicz-Skowrońska, Arka Noego $w$ stownikach $i$ w tekstach

Diana Iwanowa, Między tradycją a współczesnościa albo o bułgarskich drogach przyswajania europejskich idei językoznawczych w okresie Odrodzenia narodowego

Lucyna Agnieszka Jankowiak, O potrzebie wydzielania kwalifikatorów etymologicznych

Aleksandra Janowska, Wariantywność jako źródło supletywizmu czasowników

\section{Tom 2}

Ryszard Jedliński, $W$ świecie ponowoczesnej wolności. Refleksje edukacyjne

Wojciech Jóźwiak, Arcybiskup Josif Sokolski - hajduk, mnich, bohater, męczennik, zdrajca

Jan Kamieniecki, Elementy filologiczne w staropolskich polemikach religijnych

Maciej Kamiński, Wyrażanie znaczenia rezultatywnego $w$ poznańskich tekstach z XVII w.

Małgorzata Karwatowska, O udanym życiu (na podstawie wypowiedzi licealistów)

Krystyna Kleszczowa, Czynniki stymulujące przemiany systemu słowotwórczego

Jolanta Klimek, Jana Herbiniusa uwagi o Słowianach i ich języku

Ewa Kołodziejek, Czy jest takie słowo? O dylematach poradnictwa językowego 
Józef Kość, Wzorzec tekstowy skargi w lustracji ziemi lwowskiej z XVII wieku

Jadwiga Kowalikowa, Przekładanie językoznawstwa na dydaktykę językowa

Dorota Kozaryn, „Co jest madrość” wedtug Wizerunku własnego żywota człowieka poczciwego Mikotaja Reja

Stanisław Koziara, Glosa filologiczna do polskich ttumaczeń biblijnej sceny zwiastowania $($ Ek 1, 34)

Zapryan Kozludzhov, The Eroticism of the Inner Book Body

Zdzisława Krążyńska, Tomasz Mika, Agnieszka Słoboda, „,Mówienie o sobie” jako problem historycznoskładniowy

Danuta Krzyżyk, Helena Synowiec, O sprawności językowej uczniów w zakresie frazeologii

Marian Kucała, Co pisano o bohemizmach?

Marzanna Kuczyńska, Od Rzymu do Pekinu, Sawa Raguziński, dyplomata w stużbie Rosji

Małgorzata Kułakowska, Psalmy błagalne we współczesnych przekładach Pisma Świętego. Modlitwy czy teksty biblijne?

Władysław Kupiszewski, O pewnej osobliwości stylistycznej

Halina Kurek, Czy mogę rozmawiać z profesorem Bogdan Walczak? - „odfleksyjnianie” imion i nazwisk $w$ ujęciu socjolingwistycznym

Krzysztof Kurek, Pamiątka dla Publiczności Poznańskiej od Inspicienta Teatru Krakowskiego z 1867 roku jako interesujący przyczynek do dziejów sceny polskiej w Poznaniu

Beata Kuryłowicz, Metafory pojęciowe a poetyckie wizje zapachu kwiatów

Ewelina Kwapień, Na wsi $i$ w mieście - o źródłach kilku nowych słów w XIX wieku

Janina Labocha, Polszczyzna i czeszczyzna $w$ aspekcie porównawczym

Mariusz Leńczuk, Zagadki statutu krawieckiego z 1491 roku

Tadeusz Lewaszkiewicz, Problemy Romana Jakobsona z uzyskaniem habilitacji i profesury $w$ Brnie

Aneta Lewińska, Wielka i mała historia w nazwach ulic Tczewa

Wojciech Lipoński, Najdawniejsze tradycje języka sportu w Europie

Tomasz Lisowski, Leksem panna w znaczeniu 'dziewica' jako attributivum Marii, matki Jezusa, a polskie przekłady nowotestamentowe

Izabela Lis-Wielgosz, Twórca czy kopista - średniowieczny czy barokowy? Przypomnienie sporu wokót Gavrila Stefanovicia Venclovicia

Iwona Loewe, Stach z Warty Szukalski - lingwista i publicysta

Romana Łapa, Grupa imienna w ustawach prawnych. Adresat normy

Czesław Łapicz, Staropolski przekład Koranu jako oryginalne źródło filologiczne

Edward Łuczyński, Studia nad rozwojem mowy dziecka a refleksje nad filogeneza języka

Michał Machura, Wiesław Przyczyna, Prefacje mszalne w świetle najnowszych zasad pisowni słownictwa religijnego

Maria Maczel, Jan Pawet II we wspomnieniach Marii Kuncewiczowej

Krzysztof Maćkowiak, Kilka uwag o zbiorze Przysłowia ludu wielkopolskiego Józefa Chociszewskiego. $Z$ badań nad wielkopolska paremiografia w okresie romantyzmu

Magdalena Majdak, Głos w Pieśni duchowej św. Jana od Krzyża a biblijny szmer łagodnego powiewu

Alfred F. Majewicz, Języki zagrożone, wymierające, martwe - do konserwacji 
Władysław Makarski, O Jubilacie - antroponimicznie

Witold Mańczak, Jeszcze o etymologii słowa baczyć

Małgorzata Marcjanik, Co to sa młodzieżowe zwroty grzecznościowe

Leonarda Mariak, Językowa kreacja Dniepru w Ogniem i mieczem Henryka Sienkiewicza

Jolanta Migdał, Agnieszka Piotrowska-Wojaczyk, O przyjacielu i nie tylko wedtug leksykografów

Mariola Mikołajczak, Aleksander Mikołajczak, Z dylematów polskiego i bułgarskiego stilofila

Milica Mirkulovska, Konstrukcje taxis $w$ formie zdań zależnych $w$ języku macedońskim i polskim

Agnieszka Motyl, Problem normalizacji form czasu teraźniejszego w dobie średniopolskiej

Robert Mrózek, Onomastyka historyczna i jej zasięgi interpretacyjne

Aleksander Naumow, Malżeństwo w rodzimym piśmiennictwie Stowian prawosławnych

Małgorzata Nowak, Pieśń nad pieśniami przekładania Jerzego Żuławskiego. Kilka uwag o języku i stylu

Paweł Nowak, Ludyczność w języku mediów i w komunikacji społecznej - kooperacja czy antykooperacja?

Bogusław Nowowiejski, Pan Tadeusz jako źródło niemiecko-polskich słowników Mrongowiusza

Marek Osiewicz, Ewolucja typologiczna języka polskiego (system fonologiczny). W poszukiwaniu symetrii

Danuta Ostaszewska, „Piewca urody miasta” - Adam Jarzębski i jego dzieło. Rekonesans badań nad zjawiskiem aksjologizacji opisu w XVII-wiecznym przewodniku po Warszawie

Kazimierz Ożóg, Czy w nowych czasach mamy nowy język polski?

Anna Pajdzińska, Słowo kultura w polszczyźnie

Ewa Pajewska, Językowe wyznaczniki pragmatyki opisu obrazów sprzedawanych na Allegro

Magdalena Pastuchowa, Latynizmy w polszczyźnie potocznej

Patrycja Pelc, Perswazyjność tytułów ,,Wiadomości Literackich” jako strategia promocyjna pisma

Halina Pelcowa, Stowniki i atlasy gwarowe jako sposób interpretacji słownictwa

Jacek Perlin, Przesmażyć, przesuszyć, spadać na drzewo czyli enancjosemia przedrostków czasownikowych

Magdalena Pietrzak, Między felietonem a recenzja - o przynależności gatunkowej Mieszanin literacko-artystycznych Henryka Sienkiewicza

Alicja Pihan-Kijasowa, Kreacja pochwaty w barokowych kazaniach pogrzebowych

\section{Tom 3}

Anna Piotrowicz, Małgorzata Witaszek-Samborska, Językowy wizerunek mężczyzny w gwarze poznańskiej

Н. С. Побірченко, В. О. Сухомлинський та о. А. Захаренко: Діалог через роки і відстані

Jerzy Podracki, Status interpunkcji w dawnych podręcznikach gramatyki języka polskiego

Małgorzata Potent-Ambroziewicz, O spotkaniach poza czasem i przestrzenia

Sylwia Przęczek-Kisielak, Chronologia i geografia prepozycji ot//od oraz s-se//z-ze $w$ dialekcie matopolskim na podstawie rot przysiag sadowych

Stanisław Puppel, Notes on the nature of human sociality

Artur Rejter, Rola czynnika historycznego w badaniach z zakresu lingwistyki ptci 
Ewa Rogowska-Cybulska, O etymologii ludowej nazw miejscowych jako zjawisku skalarnym

Marek Ruszkowski, Usterki językowe w zakresie eufonii

Karolina Ruta, Marta Wrześniewska-Pietrzak, Neosemantyzmy we współczesnym socjolekcie studenckim

Małgorzata Rutkiewicz-Hanczewska, Diabeł $i$ jego imiona w toponimii wielkopolskiej $i$ małopolskiej

Joanna Rutkowska, ,,Ty, coś słodka jak białe czereśnie” - obraz Bożej Matki w Oratorium Leśniowskim Siedem pieśni Marii

Małgorzata Rybka, Jolanta Sławek, „,Pośród wszystkich sprzeczności życia szukamy jego prawdziwego sensu”. Konceptualizacja życia w listach Jana Pawła II do młodzieży

Joanna Rychter, Peryfrazy nazw abstraktów, temporalnych oraz zjawisk kulturowo-politycznych w utworach poetyckich Marii Pawlikowskiej-Jasnorzewskiej

Anna Salita, Językowy obraz ojczyzny $w$ dziewiętnastowiecznej prasie poznańskiej

Henryka Sędziak, Porównania i ich funkcje w Popiołach Stefana Żeromskiego. II. Świat uczuć

Elżbieta Sękowska, Kurpiowskie ślady wśród zaciagowych do Powstania Listopadowego

Ewa Siatkowska, Czy baza dialektalna czy piśmiennictwo odgrywaja główna role w rozwoju odmiany literackiej wybranych języków stowiańskich?

Janusz Siatkowski, Regionalne słowniki niemieckie

Andrzej Sieradzki, Nominacja Żydów w szamotulskiej księdze tawniczej z końca XVI wieku

Jerzy Sierociuk, $W$ sprawie wielkopolskiej polszczyzny regionalnej

Mirosława Siuciak, Siła $i$ moc jako wykładniki oceny ilościowej $w$ dawnej polszczyźnie

Krzysztof Skibski, Wielość ekspozycji - język poetycki wedtug Edwarda Stankiewicza

Elżbieta Skorupska-Raczyńska, Obraz pasterzy w kolędach domowych i pastorałkach (na materiale zbioru Kantyczki z nutami)

Teresa Skubalanka, Uwagi o kodzie stylistycznym polskiej liryki religijnej

Ewa Sławkowa, Stylistyczne potpourri. Szkic do „,portretu” prozy Zygmunta Haupta

Przemysław Słowiński, 17 lutego $w$ dziejach

Antoni Smuszkiewicz, Neologizmy w powieści Lód Jacka Dukaja

Barbara Sobczak, Retoryka pojednania

Urszula Sokólska, Na marginesie Nieznanego śpiewnika historycznego polskiego z końca XVI wieku uwag kilka

Maria Strycharska-Brzezina, Franciszek Ksawery Malinowski jako alfabetolog

Agnieszka Szczaus, Nazwy dyscyplin naukowych $w$ Informacyi matematycznej Wojciecha Bystrzonowskiego (1749)

Michał Szczyszek, Bigramy, czyli powtarzalne dwuwyrazowe struktury $w$ dialogach zadaniowych

Małgorzata Święcicka, Kilka uwag o językowych świadectwach dziedzictwa technicznego

(na materiale z Borów Tucholskich)

Lidia Tanuszewska, Diateza na granicy gramatykalizacji i przekład z pogranicza diatezy

Maria Trawińska, Między grafia a fonetyka - rz $i \dot{z} w$ wielkopolskich rotach sądowych

Jerzy Treder, Poznańscy uczeni w historii badań kaszubszczyzny

Wacław Twardzik, Witold Taszycki

Leszek Tymiakin, Wartość emocjonalna $w$ świetle sądów dorostych przedstawicieli obu ptci 
Marzanna Uździcka, Wybór tekstów, chrestomatia, antologia w komunikacji naukowej historyków języka polskiego

Jadwiga Waniakowa, Pochodzenie kilku gwarowych nazw mniszka pospolitego, Taraxacum officinale $W e b$

Przemysław Wiatrowski, Wybrane akty grzeczności w podręcznikach do nauczania języka indonezyjskiego

Piotr Wierzchoń, Już dwie poznańskie koncepcje wyjaśniania przejaskrawienia dwu warszawskich modeli współczesnej polszczyzny

Halina Wiśniewska, Wptywy francuskiej kultury na życie i twórczość Ignacego Krasickiego

Anna Wojciechowska, Z badań nad językiem dokumentacji polskich stowarzyszeń kobiecych z końca XIX wieku. Sposoby nominacji i wyrażania płci

Piotr Wojdak, Stereotypy na temat zdań względnych i pytajnozależnych

Maria Wojtak, Recepty na szczęście w pewnym poradniku

Maria Wojtyła-Świerzowska, O szczyptach i odrobinach

Ewa Woźniak, ,Wizerunek własny” XVIII-wiecznej polskiej doktorki i okulistki (na podstawie Procederu podróży i życia mego awantur Reginy Salomei Pilsztynowej)

Marian Wójtowicz, Zapożyczenia polskie w zachodnich gwarach briańskich

Bogusław Wyderka, Rozwój czasowników mleć, pleć i pochodnych w gwarach śląskich

Seweryna Wysłouch, Franciszek Siedlecki i jego koledzy wobec lingwistyki de Saussure'a

Оксана Заболотна, Ігор Кривошея, Сім років партнерства: Уманський Державний Педагогічний Університет і Університет Імені Адама Міџкевича в Познані

Katarzyna Zagórska, Informowanie w regionalnej telewizji rosyjskiej na poczatku XXI wieku

Zygmunt Zagórski, Z badań nad kontaminacją

Aleksander Zajda, Do laski marszałkowskiej zgłoszono projekt ustawy

Rafał Zarębski, Konsekwencje opisu wyrazów z prefiksami obcymi w ujęciu diachronicznym dla stanu wiedzy o słowotwórstwie polszczyzny

Jadwiga Zieniukowa, Z historii kaszubskiego języka literackiego i badań kaszubszczyzny

Karol Zierhoffer, Zofia Zierhofferowa, Proust $i$ toponimia Normandii

Rafał Zimny, Kilka uwag o tytułach wiadomości w serwisach internetowych (na przykładzie portalu www.gazeta.pl)

Piotr Żmigrodzki, $O$ derbach po raz trzeci

Iwona Żuraszek-Ryś, O imieniu Bogdan słów kilka

Jowita Żurawska-Chaszczewska, Wokół skóry $i$ skórki. Przyczynek do rozważań frazeologicznych 